\title{
Asperger e sua síndrome em 1944 e na atualidade
}

Sandra Dias*1

Apresentamos o quadro clínico nomeado Psicopatia autística infantil por Hans Asperger no contexto de sua descoberta, e na atualidade. Relacionamos essa síndrome com o Autismo infantil precoce de Leo Kanner, caracterizado na mesma época. Discutimos a ignorância do trabalho de Asperger pelos pesquisadores até a década de 1980.

Palavras-chave: Autismo, psicopatia autística infantil, síndrome de Asperger, autismo infantil precoce, Kanner

${ }^{* 1}$ Diretora do Espaço Psicanálise (São Paulo, SP, Br). 
A etiqueta "autismo" tornou-se uma das mais importantes criações linguísticas e conceituais na nomenclatura médica e psicológica, e tem dois nomes ligados aos estudos pioneiros: o pediatra austríaco Hans Asperger e o psiquiatra austríaco Leo Kanner. Setenta anos se passaram desde a publicação do texto de Asperger sobre autismo (1944) e só agora temos acesso a tradução em língua portuguesa, enquanto o artigo de Kanner (1943) já era conhecido desde sua publicação. Asperger foi totalmente ignorado até 1976 quando a psiquiatra inglesa Lorna Wing publica um artigo com um resumo do trabalho.

O termo autismo tem uma história atípica. Cunhado em 1906 por Plouller, quando estuda o processo do pensamento de pacientes com diagnóstico de demência, o nome só foi disseminado em 1911, pela pluma do psiquiatra suíço Eugen Bleuler que o aponta como um dos sintomas fundamentais da esquizofrenia.

Bleuler tomou da teoria freudiana o termo autoerotismo e subtraiu Eros, indicando o autismo como efeito da dissociação e tentativa de adaptação ao processo patológico. Ele descreveu um tipo particular de pensamento autístico ou derreísta, que não é guiado por objetivos, mas por afetos e desejos que aparecem de forma extrema na esquizofrenia e têm papel importante no caso de crianças autistas. Assim, os sintomas essenciais dos esquizofrênicos das crianças autistas podem ser englobados sob um comum denominador: uma ruptura das relações entre eles e o mundo exterior.

Kanner, estudando as psicoses infantis na Johns Hopkins University, nos EUA, publica Os distúrbios autísticos de contato afetivo no qual apresenta uma nova entidade nosográfica - o autismo infantil precoce - a partir da análise de 11 casos com patologia grave e condições singulares e fascinantes peculiaridades.

Ele recorta um quadro cujo termo autista indica uma estrutura anormal da personalidade da criança e uma caracterização que sublinha o isolamento e a forte resistência em estabelecer contato afetivo-social. Ainda que o autismo como a esquizofrenia envolvam comprometimento no relacionamento interpessoal e estereotipias, para ele, o autista não estabelecia contato com a realidade desde o início da vida e não apresentava pensamentos fantasiosos, diferente da esquizofrenia infantil em que o rompimento com a realidade externa ocorreria depois do terceiro ano de vida. 


\section{CLÁSSICOS DA PSICOPATOLOGIA}

(...) estas crianças vieram ao mundo com uma incapacidade inata de estabelecer o contato afetivo habitual com pessoas, biologicamente previsto (...). Se esta hipótese está correta, um estudo posterior (...) talvez permita fornecer critérios concretos relativos às noções ainda difusas dos componentes constitucionais de reatividade emocional (...) aqui temos exemplos puros de distúrbios autísticos inatos de contato afetivo. (Kanner, 1943/1997, p. 170)

Um ano depois, em 8 de outubro de 1943, Asperger apresenta a tese de livre docência na Faculdade de Medicina com casos atendidos na Clínica Infantil da Universidade de Viena que constituíam uma síndrome que nomeia Psicopatia autística infantil. Síndrome caracterizada por dificuldades de integração social das crianças, mas que, à diferença das descritas por Kanner, possuíam um bom nível de inteligência e linguagem e os sintomas apareciam após o terceiro ano de vida.

Ele as descreve como um tipo de criança peculiar e interessante que pode compensar suas deficiências por um alto nível de pensamento e experiência pessoal que podem levá-los a excepcionais êxitos na vida adulta. Sua finalidade ao apresentar as dificuldades dos psicopatas era tornar legítima a reivindicação de um tratamento educativo apropriado para seres humanos diferentes e com dificuldades específicas e características. Ele acredita que apesar de sua anormalidade são capazes de desempenhar seu papel na sociedade se encontrarem uma resposta de amor, compreensão e guia, enfatizando a relação entre psicologia e educação. O trabalho Asperger se inseria no Departamento de Educação Especial da clínica pediátrica e era influenciado pela Pedagogia Curativa de Rudolf Steiner, e visava a relação psicologia e educação, enquanto o de Kanner se focava no diagnóstico do autismo no campo psiquiátrico.

Utah Frith destaca que a disseminação do trabalho de Kanner na época foi possível por ser de língua inglesa, enquanto o de Asperger ficou totalmente desconhecido não por falta de mérito, mas porque restrito ao leitor alemão e holandês, provavelmente em virtude da Segunda Guerra Mundial. Foi traduzido para o russo em 1975 e inglês, sua tradução aparece em seu livro Autismo e síndrome de Asperger (1991, pp. 37-92) dez anos após Lorna Wing fazer referência ao trabalho de Asperger (1991, pp. 1 e 40).

Wing (1991) será responsável não só pela divulgação da tese de Asperger no mundo científico como também por sua associação ao autismo de Kanner. Ela aponta que a principal questão nesse campo é a de saber se as duas condições, Kanner e Asperger, são variedades da mesma anormalidade ou entidades separadas. Conclui que são variedades de uma mesma entidade, tornando-se responsável pela grande divulgação do autismo e da introdução da noção de espectro no campo científico (p. 110). Ela considera as duas descrições nosológicas pontas de extremidades que indicam o ponto mais grave e o mais leve de uma mesma patologia. Discordando em alguns pontos de Asperger, ela centra seu estudo nas perturbações autísticas baseadas 
numa tríade de perturbações, perturbações globais do desenvolvimento, composta por elementos deficitários que toda pessoa com autismo apresenta: Comunicação ou Linguagem, Interação Social e Pensamento e Imaginação.

No artigo "A relação entre síndrome de Asperger e o autismo de Kanner", Wing faz uma comparação dos escritos de Asperger (1944/979) com os primeiros artigos de Kanner e conclui que há similaridades surpreendentes entre as crianças descritas pelos dois autores em dez pontos (pp. 93-95). A partir desse momento a psicopatia autística infantil será conhecida no mundo como Síndrome de Asperger e ligada ao autismo de alto funcionamento.

Wing indica que existem diferenças entre os relatos dos pioneiros. As crianças descritas por Asperger desenvolveram linguagem antes da idade escolar, tinham vocabulário amplo e razoável gramática, apesar de socialmente isolados fazem tentativas de aproximação. Elas têm uma aparência estranha em contraste com a aparência viva e cativante das crianças de Kanner. Apresentam uma "originalidade de pensamento" e seus interesses são canalizados para assuntos preferivelmente abstratos e de pouco uso prático.

Em 1930, Melanie Klein descreve o caso clínico de uma criança com quatro anos, chamada Dick, encaminhada com o diagnóstico de demência precoce, mas cujos sintomas apontam para o autismo:

(...) era carente de afetos e indiferente à presença ou ausência de sua mãe (...) estavam quase completamente ausentes a adaptação à realidade e as relações emocionais com seu ambiente (...) não tinha interesse pelos brinquedos (...) não brincava e não tinha contato com o seu ambiente. Na maior parte do tempo, articulava sons ininteligíveis. (Klein, 1930/1996)

Dick não podia ser incluído na descrição psiquiátrica de esquizofrenia de Bleuler e "contra o diagnóstico de demência precoce havia o fato de a principal característica do caso de Dick ser a inibição do desenvolvimento e não a regressão" (p. 262), nele não se observava o que definia a esquizofrenia, a presença do isolamento da realidade acompanhado de pensamentos fantasiosos. Ao enfatizar a inibição egoica de Dick, Klein toma o quadro de isolamento e a impossibilidade de simbolizar a realidade para além da visão sintomatológica da doença, e instaura a possibilidade de tratamento para um tipo de patologia grave na infância que só seria identificada e separada da esquizofrenia infantil após os trabalhos pioneiros, deixando uma herança continuada por psicanalistas no campo do autismo como Mahler, Tustin, Meltzer Bettelheim, Lefort, Bergés, Lasnik-Penot, Nominé, Lacadée, Maleval.

Essa dificuldade do diagnóstico diferencial levara os pesquisadores a se centrarem não só na diferenciação entre autismo e esquizofrenia, mas a um debate apaixonado quanto ao lugar do autismo e da síndrome de Asperger no campo da 


\section{CLÁSSICOS DA PSICOPATOLOGIA}

psicopatologia, derivando diferentes correntes teóricas sobre o autismo com fortes incidências sobre a política de saúde e educação.

No Manual Diagnóstico e Estatístico de Transtornos Mentais observamos que em 1968, no DSM II, o autismo foi inserido no quadro "esquizofrenia de início na infância". A partir da década de 1980, o autismo é retirado da categoria de psicose e no DSM III utiliza-se a nomeação de distúrbios invasivos do desenvolvimento. No DSM IV (1991) caracterizado por prejuízo severo e invasivo em diversas áreas do desenvolvimento é considerado um distúrbio global do desenvolvimento. No DSM 5 (2013) o autismo é situado na categoria de Transtornos do Neurodesenvolvimento e assumido como espectro, substituindo assim as subcategorias dos "Transtornos Invasivos do Desenvolvimento" que são agora abordadas por um único termo abrangente: Transtornos do Espectro do Autismo, nos quais se assinalam "especificadores" para identificar suas variações, como a presença ou ausência de comprometimento intelectual, comprometimento estrutural da linguagem, condições médicas ou perda de habilidades anteriormente adquiridas (Regier et al., 2013; Laia, 2011).

Assim, o autismo passa a ser considerado sinal de déficit cerebral, as crianças autistas vistas como deficitárias, a síndrome considerada crônica, incurável, e o tratamento restrito à área médica e pedagógica, com dois impedimentos de base: da deficiência e o da cronicidade.

Todavia, o autismo continua a fascinar os estudiosos, como fascinaram Kanner e Asperger, e a interrogá-los em seus limites teóricos, epistemológicos e éticos constituindo-se em um enigma que a ciência não consegue elucidar.

\section{Referências}

Asperger, H. (1991). Autistic psychopathy in childhood. In U. Frith (Ed.), Autism and Asperger syndrome (pp. 37-92). Londres: Cambridge University Press. (Trabalho original publicado em 1944).

Frith, U. (1991). Asperger and his syndrome. In U. Frith (Ed.), Autism and Asperger syndrome. (pp. 1-36). Londres: Cambridge University Press.

Kanner, L. (1997). Os distúrbios do contato afetivo. In P.S. Rocha (Org.), Autismos (pp. 111-170). São Paulo: Escuta. (Trabalho original publicado em 1943).

Klein, M. (1996). A psicoterapia das psicoses. In M. Klein, Amor, culpa e reparação e outros trabalhos (pp. 265-268). Rio de Janeiro: Imago. (Trabalho original publicado em 1930).

Laia, S. (2011). A classificação dos transtornos mentais pelo DSM-5 e a orientação lacaniana. CliniCAPS, 5(15). Recuperado em 20 mar. 2014 de: <http://www.clinicaps.com. br/clinicaps_pdf/Rev_15/LaiaS.pdf>. 
Regier, D.A., Kuhl, E.A., Kupfer, D.J. (2013, Jun.). The DSM-5: Classification and criteria changes. World Psychiatry, 12(2), 92-98. Recuperado em 20 mar. 2014 de: <http:// www.ncbi.nlm.nih.gov/pmc/articles/PMC3683251/>.

Wing, L. (1991). The relationship between Asperger's syndrome and Kanner's autism. In U. Frith (Ed.), Autism and Asperger syndrome (pp. 93-121). Londres: Cambridge University Press.

\section{Resumos}

(Asperger and his syndrome in 1944 and today)

We present the clinical picture Hans Asperger named 'autistic child psychopathy' in the context of its discovery, a designation which has persisted to date, and relate that syndrome to Leo Kanner's early infantile autism, which was discovered at the same time. We discuss the way Asperger's work has remained neglected by researchers until the 1980s.

Keywords: Autism, autistic chidl psychopathy, Asperger syndrome, early infantile autism, Kanner.

(Asperger et son syndrome en 1944 et aujourd'hui)

Nous présentons le tableau clinique nommé psychopathie autistique de l'enfance par Hans Asperger dans le contexte de sa découverte, terme qui s'applique encore aujourd'hui. Nous relions ce syndrome à l'autisme infantile précoce de Leo Kanner, décrit à la même époque et nous discutons le fait que le travail d'Asperger a été largement ignoré par la communauté scientifique jusque dans les années 1980.

Mots clés: Autisme, psychopathie autistique de l'enfant, syndrome d'Asperger, autisme infantile précoce, Kanner.

(Asperger y su síndrome en 1944 y en la actualidad)

Presentamos el cuadro clínico conocido, por Hans Asperger, como psicopatía autista en el niño en el ámbito de su descubrimiento y en la actualidad. Relacionamos este síndrome con el autismo infantil temprano de Leo Kanner, que se caracteriza en la misma época. Se discute la ignorancia de la obra de Asperger por parte de los investigadores hasta la década de 1980.

Palabras clave: Autismo, psicopatía autista en el niño, síndrome de Asperger, autismo infantil temprano, Kanner

(Asperger und sein Syndrom - 1944 und heute)

Wir präsentieren das klinische Bild, dass Hans Asperger im Kontext seiner Entdeckung , kindliche autistische Psychopathie“ nannte, eine Bezeichnung die sich bis 


\section{CLÁSSICOS DA PSICOPATOLOGIA}

heute erhalten hat. Wir ordnen dieses Syndrom dem frühkindlichen Autismus von Leo Kanner zu, der in der gleichen Epoche definiert wurde. Wir diskutieren außerdem die Tatsache, dass Aspergers Arbeit von der Forschungsgemeinschaft bis in den 1980er Jahren unbeachtet blieb.

Schlüsselwörter: Autismus, kindliche autistisch Psychopathie, Asperger-Syndrom, frühkindlicher Autismus, Kanner

\section{阿斯伯格综合症在1944年和在目前的现状）}

我们回顾了汉斯·阿斯伯格1944年发现的儿童精神自闭症并以其名字命名的 阿斯伯格综合症的历史, 分析了当时和目前这种儿童自闭症的临床表现。我们把 阿斯伯格综合症与同时期列奥.坎纳发现的早期儿童自闭症孤独症联系对比，发现 直到1980年代, 很多研究人员对阿斯伯格综合症的治疗工作一无所知。

关键词：自闭症，神经性儿童自闭症，阿斯伯格综合症，幼儿早期自闭症，卡纳

Citação/Citation: Dias, S. (2015, junho). Asperger e sua síndrome em 1944 e na atualidade. Revista Latinoamericana de Psicopatologia Fundamental, 18(2), 307-313.

Editor do artigo/Editor: Prof. Dr. German E. Berrios

Recebido/Received: 3.3.2015/3.3.2015 Aceito/Accepted: 25.3.2015 / 3.25.2015

Copyright: (C) 2009 Associação Universitária de Pesquisa em Psicopatologia Fundamental/ University Association for Research in Fundamental Psychopathology. Este é um artigo de livre acesso, que permite uso irrestrito, distribuição e reprodução em qualquer meio, desde que o autor e a fonte sejam citados / This is an open-access article, which permits unrestricted use, distribution, and reproduction in any medium, provided the original authors and sources are credited.

Financiamento/Funding: A autora declara não ter sido financiada ou apoiada / The author has no support or funding to report.

Conflito de interesses/Conflict of interest: A autora declara que não há conflito de interesses

/ The author has no conflict of interest to declare.

\section{SANDRa Dias}

Doutora em Psicologia Clínica pela Pontifícia Universidade Católica de São Paulo - PUCSP (São Paulo, SP, Br); Diretora do Espaço Psicanálise (São Paulo, SP, Br) e Supervisora Técnica da Oscip Gestae: Instituto de Pesquisa, Ensino e Ação em Saúde Mental (São Paulo, $\mathrm{SP}, \mathrm{Br})$.

e-mail: sandra.dias@uol.com,br 